\title{
Analytical and Experimental Evaluation of Aerodynamic Thrust Vectoring on an Aerospike Nozzle
}

\author{
Shannon D. Eilers, Matthew D. Wilson*, Dr. Stephen A. Whitmoreł and Zachary W. Peterson*
}

Results from numerical and cold-flow experimental investigations of aerodynamic thrust vectoring on a small-scale aerospike thruster are presented. Thrust vectoring was created by the injection of a secondary fluid into the primary flow field normal to the nozzle axis. The experimental aerospike nozzle was truncated at $57 \%$ of its full theoretical length. Data derived from cold-flow thrust vectoring tests with carbon dioxide as the working fluid are presented. Injection points near the end of the truncated spike produced the highest force amplification factors. Explanations are given for this phenomenon. For secondary injection near the end of the aerospike, side force amplification factors up to approximately 1.4 and side force specific impulses up to approximately $55 \mathrm{~s}$ with main flow specific impulses clustering around $38 \mathrm{~s}$ were demonstrated. These forces crisply reproduce input pulses with a high degree of fidelity. The side force levels are approximately $2.7 \%$ of the total thrust level at maximum effectiveness. Higher side forces on the order of $4.7 \%$ of axial thrust were also achieved at reduced efficiency. The side force amplification factors were independent of operating nozzle pressure ratio for the range of chamber pressures used in this test series.

\section{Nomenclature}

$$
\begin{array}{ll}
\Delta A & =\text { area of intersection for high pressure region behind shock wave } \\
\dot{m}_{j} & =\text { secondary injection mass flow rate } \\
A_{j} & =\text { secondary injection area } \\
C & =\text { adjustable flow constant } \\
F_{i} & =\text { amplified side force } \\
F_{v} & =\text { side force without amplification by primary flow } \\
h & =\text { accomodation height }
\end{array}
$$

${ }^{*}$ Graduate Student, Mechanical and Aerospace Engineering (MAE) Department, 4130 Old Main Hill, Logan, UT 84322-4130, AIAA Student Member

${ }^{\dagger}$ Assistant Professor, Mechanical and Aerospace Engineering (MAE) Department, 4130 Old Main Hill, Logan, UT 843224130, AIAA Member 


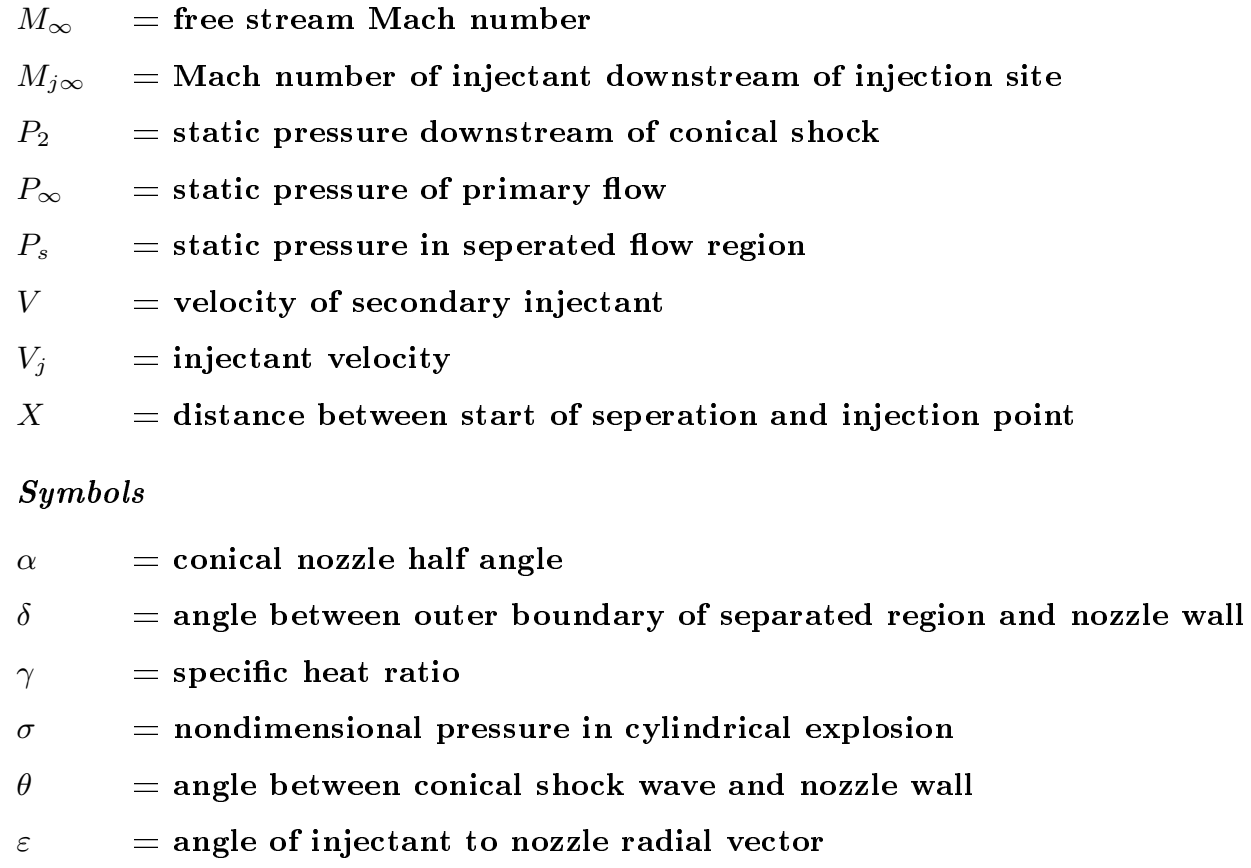

\section{Introduction}

\section{I.A. Aerospike Nozzle History}

The first major round of testing was completed on aerospike nozzles in the 1950s and 1960s when truncated plug nozzles were under consideration for the Saturn V upper stages, ${ }^{1}$ and then later the Space Shuttle's main engine. $^{2-4}$ During this period, Rocketdyne conducted extensive research into both aerospike performance and liquid injection thrust vectoring capability ${ }^{5}{ }^{6}$ As a result of this test series, Rocketdyne concluded that Aerospike nozzles had less or equal thrust vectoring capability than bell nozzle counterparts. However, their tests were limited to liquid injection as they did not perform cold flow thrust vectoring tests and hot gas injection hardware was not yet available. After a conventional bell nozzle was chosen for the Space Shuttle Main Engine, work on aerospike nozzles decreased substantially until the 1990s when work began on the X-33 single stage to orbit concept. ${ }^{7}$ To further this effort, additional work and testing was performed by Rocketdyne for Lockheed during the development of the RS 2200 linear aerospike. ${ }^{8-10}$

After the development of the X-33 and the Venture Star was canceled, work on aerospike nozzles once again became more sporadic. In America, NASA Langley has worked on further parametric modeling and optimization of aerospike nozzles. ${ }^{11}$ Analytical research including developing computational algorithms to evaluate thrust vector control for aerospike nozzles was performed at the University of Huntsville ${ }^{12}$ and differential throttling research has been completed under the direction of Marsh Space Flight Center. ${ }^{13}$ Engineers at NASA Dryden and AFRL designed and flew an aerospike nozzle on a high power rocket. ${ }^{14}$ Attempts have been made to develop annular aerospike nozzles for hybrid rockets at Arizona State University ${ }^{15}$ and 
the University of Washington ${ }^{16}$ although there were notable challenges due to erosion of the nozzle support structure occurred in the former and nozzle ablation rates were not presented in the latter. California Polytechnic has also investigated coupling an aerospike nozzle with a hybrid rocket motor. Their efforts centered on active cooling techniques. ${ }^{17,18}$ California State University, Long Beach in association with the Garvey Spacecraft Corporation has also completed extensive testing of liquid, clustered aerospike engines which have culminated in the launch of several sounding rockets. ${ }^{19-23}$

Outside of the United States, aerospike nozzles have enjoyed a large amount of attention in recent decades. The European Space Agency has investigated the relative effectiveness of various aerospike thrust vector control techniques. ${ }^{24,25}$ In the mid 1990's The Technical University of Munich has performed analytical research on performance aspects of aerospike nozzles including performance losses due to nozzle clustering. ${ }^{26,27}$ Some research has also been completed at the DLR in Germany mostly concerning effects of aerospike cluster configurations. ${ }^{28-30}$ A substantial amount of work has also been completed in Italy on performance validation, flight behavior, and motor cluster performance for aerospike nozzles. ${ }^{31-35}$

A great deal of analytical work has been performed at several Universities in Japan on aerospike performance, slipstream effects, slipstream effect mitigation, and base bleed injection. ${ }^{36-44}$ Experimental work has also been completed in Japan in an effort to investigate the flow field of clustered linear aerospike nozzles. ${ }^{45}$ Research leading to conceptual level design work for an aerospike nozzle to support SSTO vehicle design has been undertaken recently at the Japan Aerospace Exploration Agency. ${ }^{46-48}$ Beijing University in China has performed analysis as well as cold flow tests on aerospike nozzles investigating nozzle performance, base bleed effects, and thrust vectoring ${ }^{49-53}$ mostly in regard to linear aerospike engines.

The National Aerospace Laboratories in Bangalore, India have investigated the acoustics of aerospike nozzles ${ }^{54}$ and performance characteristics of conical aerospike nozzle contours. ${ }^{55}$ Some analytical work has also been completed in Russia on optimal aerospike contours. ${ }^{56}$ The Aerospace Research Institute in Iran has also completed some work on base bleed performance. ${ }^{57}$

\section{I.B. Potential Aerospike Nozzle Space Applications}

While aerospike nozzles have long been known for their altitude compensation ability during endo-atmospheric flight,${ }^{58}$ they also present significant potential advantages for purely in-space applications. Aerospike nozzles can be both more efficient and significantly smaller than conventional high expansion ratio bell nozzles. Given a fixed vehicle base area, an aerospike nozzle can present higher area expansion ratio than a bell nozzle, providing better performance in a space environment or near vacuum environment like Mars. The increased specific impulse $\left(I_{s p}\right)$ due to a higher possible expansion ratio using an aerospike nozzle translates

to a $8-9 \%$ decrease in the propellant mass and total system weight for space and near-space applications. ${ }^{14}$ 
Additionally, one of the often-overlooked properties of the aerospike nozzle is the ability to achieve thrust vectoring aerodynamically without active mechanical nozzle gimbals. This offers a significant potential for reduced system complexity and weight. In contrast to secondary injection in a bell nozzle, thrust vectoring performed by secondary fluid injection on an aerospike nozzle could also be used for attitude control independent of main thruster operation, albeit at reduced effectiveness. This makes fluidic thrust vectoring on aerospike nozzles a potential replacement for both gas attitude control thrusters and main engine thrust vector control, yielding even greater advantages in system mass and simplicity.

Figure 1 compares two aerospike-based nozzle designs to their conventional counterparts with the same effective expansion ratios. Fig 1a compares the original Saturn V first stage F-1A engine to its proposed replacement J-2T-250K aerospike engine (featuring a truncated plug nozzle). It should be noted that both of these engines are optimized for earth atmospheric conditions. At Mars and vacuum conditions, the size difference is greater. This size difference is illustrated by $1 \mathrm{~b}$ where the proposed $12.1 \mathrm{kNt}$ Altair Lander Engine is compared to its aerospike equivalent. In both examples, the size differences are pronounced.

Despite these potential benefits over conventional conical or bell-nozzle designs, because of a perceived low technology readiness level the aerospike rocket configuration has never been deployed on an operational space vehicle. One of the major reasons for this perception is the lack of high quality ground and flight test data and its correlation with analytical flow predictions. This dearth of data is especially true with regard to off-nominal design performance, thrust vectoring, and thruster-out scenarios for clustered aerospike configurations.

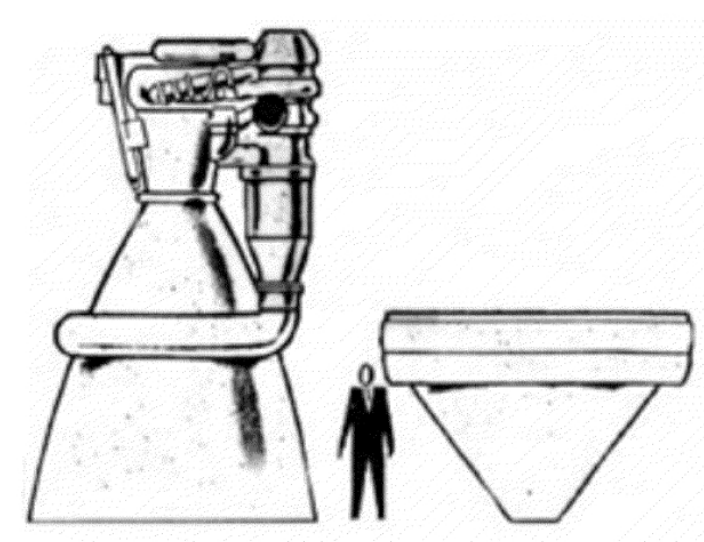

(a)

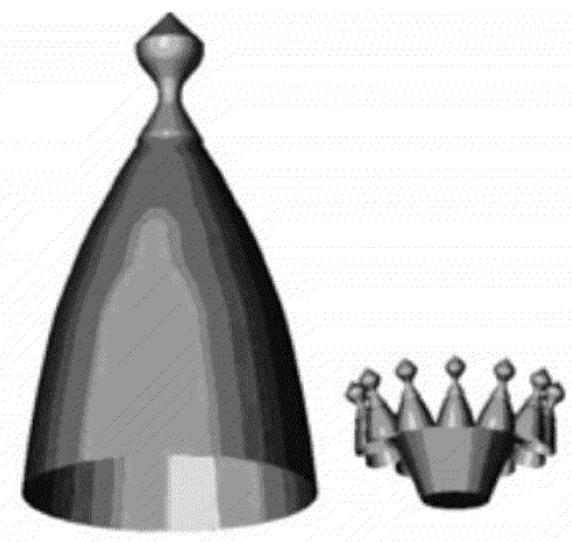

(b)

Figure 1: Aerospike compared to conventional nozzles. a) Comparison of F-1 engine to proposed J-2T-250K aerospike. b) Comparison of $12.1 \mathrm{kNt}$ lunar ascent engine for Altair Lander with proposed aerospike design. 


\section{Cold Flow Testing}

The primary objective of cold flow aerospike testing was to examine the viability of fluidic thrust vectoring by gas injection on a truncated annular aerospike nozzle in near-optimally expanded conditions. Although the final aerospike nozzle was slightly over expanded, it was designed such that the near-surface flow field was nearly identical to flow fields that would be experienced by an under-expanded or optimally-expanded nozzle. In this way, the thrust vectoring research centered on thrust vectoring that would be primarily applicable to high altitude or in-space conditions.

Research emphasized examination of the effect of injection location on thrust vectoring effectiveness as well as side force fidelity and dependence on the nozzle pressure ratio.

\section{II.A. Cold Flow Experimental Setup}

All aerospike static tests were performed in the Engineering Technology Department's Jet Engine test cell on the Utah State University (USU) campus. For static thrust tests, commercially available test stands were examined and found to be excessively expensive and have structural support mechanisms that were unsuitable for mounting the aerospike prototype. Consequently, a custom-made, portable, test stand was designed and built to support the needs of the aerospike project.

The test stand features a six-degree-of-freedom load balance with Omega LCCD type S load cells configured as shown in Fig. 2. Three 100 lbf-range axial and three 25 lbf-range lateral load cells are arranged such that six-degree-of-freedom force and moment measurements can be resolved. The thrust stand coordinate system, pictured in 2 , is defined with x-axis vertically upward along the axial centerline of the nozzle. The thrust stand is designed so that the nozzle exhaust plume exits vertically, and the thrust acts downward onto the test cart. The test stand was calibrated in-situ with a simultaneously multi-axial calibration method. The total resultant uncertainty (to $95 \%$ confidence) for forces using this calibration method was statistically determined as approximately 0.25 newtons for side forces and 1.75 newtons for axial loading.

For ease of storage, carbon dioxide was chosen for a working fluid. Figure 3 presents a schematic diagram of the associated cold-gas feed system. Saturated liquid carbon dioxide is stored in standard K-sized storage tanks, with each tank having a storage capacity of approximately $25 \mathrm{~kg}$. Multiple tanks were manifolded to assure that the required mass flow levels and run times can be achieved. Flow out of the tanks is controlled via a pneumatic ball valve. The pneumatic valve actuator is controlled with a 12-volt Direct Current (DC) solenoid valve. Beyond the ball valve, carbon dioxide flows through a manually set needle valve that drops the pressure from the saturation pressure of carbon dioxide, $4825-5515 \mathrm{kPa}(700-800 \mathrm{psia})$ at room temperature, to approximately $1035 \mathrm{kPa}$ (150 psi). Carbon dioxide then flows into a water-bath heat exchanger which raised the temperature of the expanded carbon dioxide by approximately $25 \mathrm{C}$. The pressure downstream of 
the needle valve is controlled using a back-flow pressure regulator and a primary regulator in parallel. This configuration maintains approximately $1034 \mathrm{kPa}(150 \mathrm{psi})$ upstream of the primary regulator. The primary flow regulator then further drops the feed pressure to approximately $690 \mathrm{kPa}(100 \mathrm{psi})$ at the plenum inlet.

At full pressure, the primary regulator is set to allow approximately one kilogram per second mass flow through the aerospike nozzle throat. The back-pressure regulator will vent approximately half that flow rate at start up. As the tanks evacuate and the overall system pressure drops, flow through the back-pressure regulator diminishes to zero. An additional electronic regulator in parallel with the main flow regulator controls the upstream pressure of the secondary (thrust vectoring and base-bleed) flow injection ports.

Type K thermocouples and Omega PX400 series pressure transducers are used to monitor temperatures and pressures throughout the flow system. A custom manufactured venturi, also using Omega PX400 pressure transducers to measure the pressure differential, is situated upstream of the electronic regulator. Although a differential pressure transducer was not used, the pressure transducer voltage bias is removed at full operating pressure when the secondary flow injection is turned fully off which results in a highly accurate differential pressure measurement. The venturi was calibrated in-situ using high flow coefficient sonic orifices. In this manner, the flow coefficient for the venturi was calculated to be 0.980 .

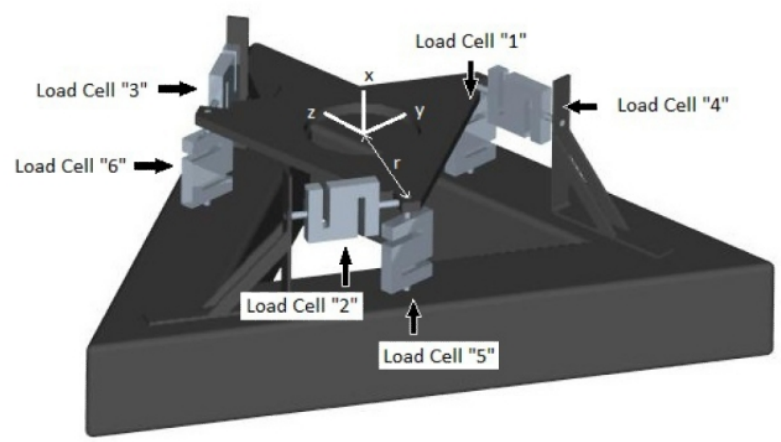

Figure 2: Six degree of freedom test stand.

\section{II.B. Test Article Description}

The aerospike used for cold flow testing was sized such that it was slightly over expanded for operating conditions at the test altitude in Logan, Utah. As the test conditions were created to approximate space conditions, the aerospike was designed using a method of characteristics code such that compression waves generated by over expansion would not intersect the end of the truncated spike at full chamber pressure. This resulted in an aerospike pressure distribution roughly independent of atmospheric pressure except for the 


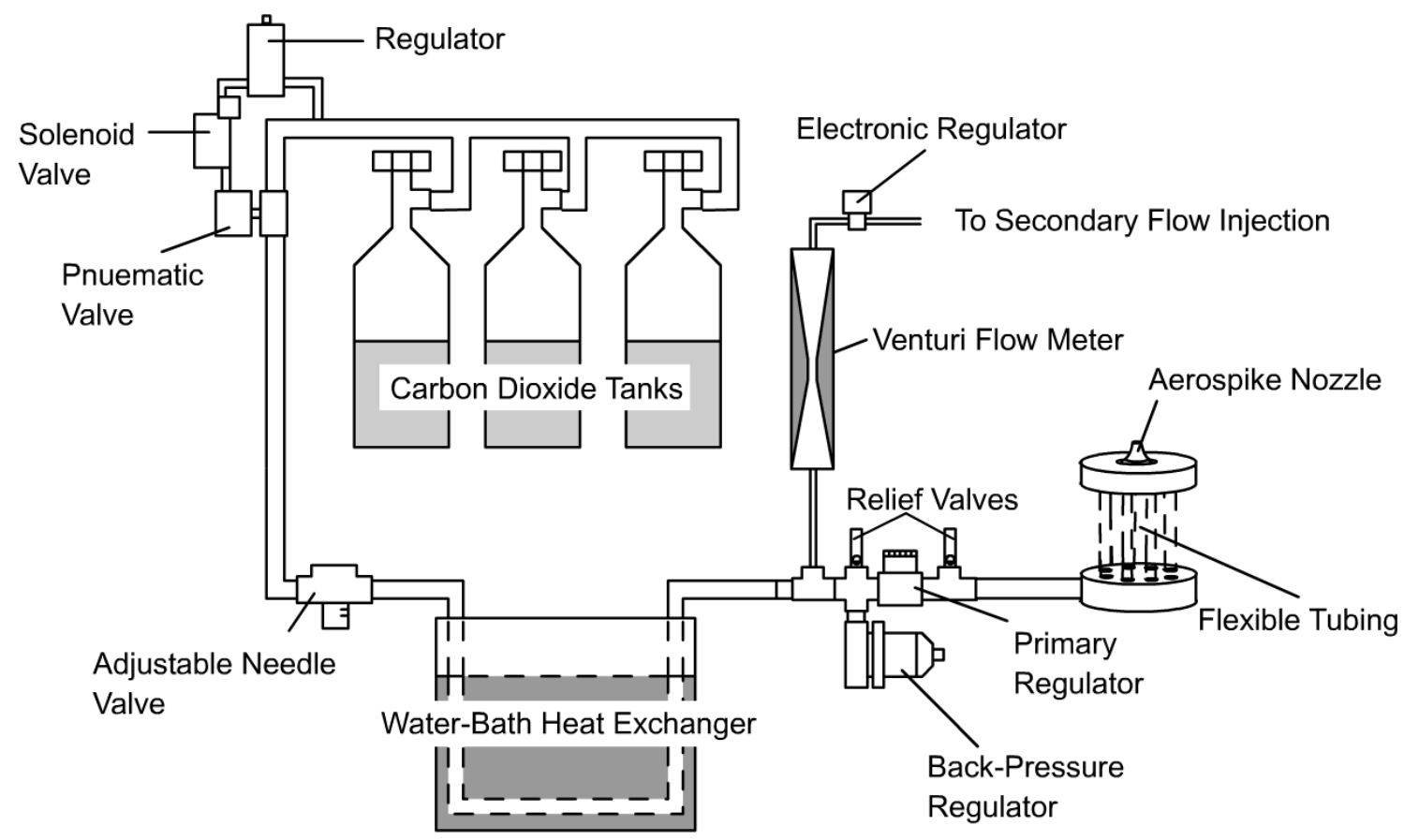

Figure 3: Aerospike propellant feed system.

base area and the very end of the spike length. This effect was confirmed through the use of computational fluid dynamics. The salient aerospike characteristics are shown in Table 1 and the aerospike and plenum are shown in Fig. 4.

Table 1: Cold-Flow Aerospike Parameters

\begin{tabular}{cc}
\hline Aerospike Parameter & Value \\
\hline Plug Diameter & $3.2 \mathrm{~cm}$ \\
Outer Throat Diameter & $3.86 \mathrm{~cm}$ \\
Truncated Length & $2.54 \mathrm{~cm}$ \\
Full Isentropic Spike Length & $4.31 \mathrm{~cm}$ \\
Truncation Ratio & $57 \%$ \\
Throat Diameter & $0.29 \mathrm{~cm}$ \\
Operating Stagnation Pressure & $775 \mathrm{kPa}$ \\
Nozzle Expansion Ratio & 2.47 \\
Plenum Exit Throat Area & $4.73 \mathrm{~cm}$ \\
Secondary Injection Port Diameter & $0.3175 \mathrm{~cm}$ \\
Design Altitude & $4206 \mathrm{~m} \mathrm{MSL}$ \\
Design Thrust & $454 \mathrm{~N}$ \\
\hline
\end{tabular}

\section{II.C. Cold Flow Test Results}

Aerospike configurations with injection ports at $20 \%, 80 \%$ and $90 \%$ of truncated length were tested with secondary mass flow rates between $0.005 \mathrm{~kg} / \mathrm{s}$ and $0.016 \mathrm{~kg} / \mathrm{s}$. These flow rates correspond to secondary 


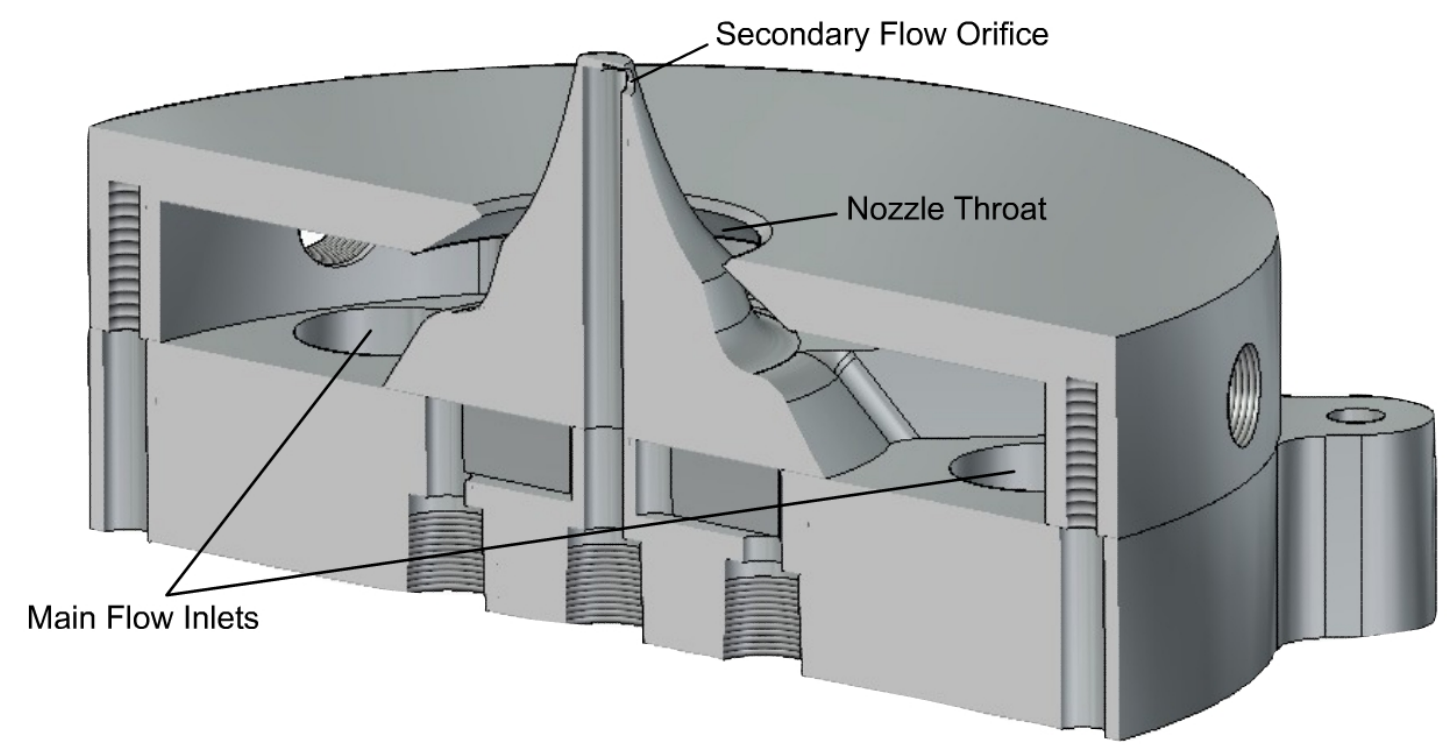

Figure 4: Cold flow aerospike test configuration.

flow inlet pressures between approximately 400 and $800 \mathrm{kPa}$. The secondary injection orifices were machined such that they injected fluid normal to the aerospike's longitudinal axis. Lateral force, secondary injection pressure, mass flow rate and temperatures for two typical tests are shown in Fig. 5. The response fidelity between the electronic regulator control and the output size force is clearly shown. This was typical of the entire test series.

The side force, specific impulse, and secondary flow pressure for $90 \%$ secondary injection location for both main flow on and main flow off is shown in Fig 6 . The resulting side force amplification factor and specific impulse for each configuration is shown in Table 2 and Fig. 7. Here side force amplification factor was defined as the ratio of side force with a main axial flow to the side force generated by the secondary injection without the primary flow. This is similar to the definition used by Walker ${ }^{59}$ in thrust vectoring research at Johns Hopkins University. Using this definition instead of the other traditional definition of the ratio of side force to axial force specific impulse avoids the the dependence on the arbitrary efficiency of the primary thruster. An additional configuration with a larger diameter injection orifice and at approximately $90 \%$ the length of the truncated spike was also tested to examine side force scaling. These results are shown in 8.

The use of carbon dioxide as a operating fluid lead to a useful fluid visualization technique, as carbon dioxide starts to crystallize near the end of the aerospike contour. This creates a semi-opaque white cloud that is readily visible. The temperature increase caused by shock waves resulting from secondary fluid 
injection create clear areas in the flow field and are thereby clearly distinguishable from the rest of the flow field. The leading edge bow shock caused by fluid injection for a high flow rate test can clearly be seen in figure 9 .

Limiting the effect of the low pressure zone behind the injection port simply requires that the injection point be located near the end of the nozzle. This result is clearly supported by the cold flow data. For hole locations far away from the truncation length of the spike, such as the $20 \%$ injection site, the low pressure region has more effect than the bow shock caused by the injection. Thus, the interaction of the main flow and the secondary fluid injection causes a side force amplification factor less than unity. When the injection location is near the end of the aerospike, the effect of the low pressure region is diminished which results in large efficiency gains.

During the cold flow test series, the nozzle pressure ratio was varied from approximately 5.0 to 8.0. No meaningful correlation between side force specific impulse and chamber pressure was observed over this range. The side force $I_{s p}$ for this range with the $90 \%$ injection location is shown in Fig. 10. Near the upper part of this range, the nozzle surface pressure is effectively independent of ambient pressure. At lower pressure ratios, aerospike altitude compensation will affect the local ambient Mach number and density around the secondary flow orifice. The variation of these two parameters appear to have counterbalancing influences on the side force specific impulse over the range of pressure ratios examined during cold flow testing.

It is notable that the secondary injectant does not reach sonic velocity at the immediate exit of the injection orifice. The bow shock caused by primary flow results in an effectively reduced area for the injectant immediately downstream of the orifice. This resulted in a typical drop in discharge coefficient of about 5 percent between tests with secondary injection only and secondary injection with active primary flow.

For aerospike configurations with the secondary injection point near the end of the aerospike, the effect of fluid injection on axial thrust was small enough such that it was not detectable by the current testing apparatus.

\section{II.D. Dependence on longitudinal injection site}

The high dependence of thrust vectoring efficiency with longitudinal hole location seen during this test series is in direct contradiction to side force relations obtained on conical nozzles. For lab scale tests on conical nozzles, the optimum injection point for gas injection has been found to be nearest the throat where the resulting bow shock does not impinge on the opposite nozzle wall. ${ }^{60}$ For the series of cold flow tests discussed above, it was found that the optimal injection location was at the aft edge of the truncated aerospike length. Two possible explanations for this effect are the effect of local free stream Mach number at the injection 
location and diminishing the effect of the low pressure, over expanded region directly downstream of the injection location.

Several of the prominent theoretical models for thrust vectoring due to fluid injection both predict a strong positive dependence on free stream Mach number. One of these models is the blast wave theory analogy promoted by Broadwell. ${ }^{61}$ Broadwell noted the similarity between the shock wave shape exhibited by secondary injection into supersonic flow and the shock waves generated by linear charges. This neglects any dependence on boundary layer effects at the injection site which are not insignificant. Hence, this, like the other theoretical models proposed in the 1960s should be used to predict trends only and do not make good predictors of actual side force amplification. The defects of theoretical models for side force injection was examined in detail by Guhse. ${ }^{62}$ With the aforementioned note, the blast wave theory model predicts that side force amplification should generally obey the relation

$$
\frac{F_{i}}{F_{v}}=\frac{C \sigma(\gamma) M_{\infty} V_{\infty}}{\left(V_{j}\right)_{v}}\left[1+\frac{2+(\gamma-1) M_{\infty}^{2}}{2(\gamma-1) M_{\infty}}\right]
$$

which has a strong positive dependence on Mach number. Walker, Stone, and Shander ${ }^{59}$ modified a linear flow relation by Vinson, Amik and Liepman ${ }^{63}$ that assumed that the side force could be approximated by linear supersonic flow analysis over the area displaced by a secondary flow injectant expanded to the pressure of the primary flow. Their relation, once solved for the amplification factor defined above, yields

$$
\frac{F_{i}}{F_{v}}=\frac{1}{(1+\gamma)} \frac{\gamma M_{\infty}^{2}}{\left(M_{\infty}^{2}-1\right)^{\frac{1}{2}}}\left[\frac{1+\gamma}{M_{j \infty}^{2}\left[2+(\gamma-1) M_{j \infty}^{2}\right]}\right]
$$

which is also strongly dependent upon the free stream Mach number.

Another prominent model which seems to reproduce trends for secondary injection for conical nozzles is the relation proposed by $\mathrm{Wu}$, Chapkins and Mager. ${ }^{64}$ Their method uses conical shock analysis to approximate the pressure distribution behind the primary bow shock with a parabolic fit. They adjust for geometry but presume that the effects of the bow shock and the over expansion region behind the injection point cancel downstream of the injection orifice. In their model side force can be determined from the relation

$$
F_{i}=\left[\left(\frac{P_{2}}{P_{\infty}}-1\right)(\Delta A-X h)+\left(\frac{P_{s}}{P_{\infty}}-1\right)\left(X h-\frac{A_{j}}{2}\right)\right] P_{\infty} \cos (\alpha)+P_{\infty} A_{j} \cos (\varepsilon)\left(\frac{P_{j}}{P_{\infty}}-1\right)+\dot{m}_{j} V_{j}
$$

where

$$
h=\left[\frac{2 A_{\infty}}{\pi}\right]^{\frac{1}{2}}\left[\frac{2 \gamma^{2} M_{j}^{2}\left(1+\frac{\gamma-1}{2} M_{j}^{2}\right)}{\left(\frac{A_{\infty}}{A_{j}}\right)^{2}\left(\frac{P_{\infty}}{P_{j}}\right)^{2}\left(\frac{P_{s}}{P_{\infty}}-1\right)\left[\gamma+1+\left(\gamma_{-1}\right) \frac{P_{s}}{P_{\infty}}\right]}\right]^{\frac{1}{4}}
$$




$$
\begin{gathered}
X=h[\cot (\delta)+\tan (\alpha+\varepsilon)] \\
\Delta A=h^{2}[\cot (\delta)+\tan (\alpha+\varepsilon)]^{2} \tan \theta
\end{gathered}
$$

The dependence of this relation on primary flow Mach number is not immediately clear. The primary Mach number is buried in the free stream static pressure, $P_{\infty}$. Ultimately this relation results in a decreased predicted effectiveness as the injection location moves downstream towards the nozzle exit. They propose that the optimum injection location is the point farthest forward where the shock wave created by injection does not reflect off of the opposite side of the conical nozzle. Experiments conducted at the Massachusetts Institute of Technology agreed with this result. ${ }^{60}$ The dependence of all three of these relations for a specific heat ratio of 1.2 and normalized to equal unity at a Mach number of 2.0 is shown in Fig. 11.

The wide divergence in trends predicted by these models tends to limit confidence in their use as prediction tools. However, the model proposed by Wu does seem to agree somewhat with experimental data concerning injection sites. If it is presumed that there is a positive relationship between side force amplification and free stream Mach number, as in the models by Broadwell and Walker, this could explain at least some of the axial dependence measured during the aerospike cold flow test series. The free stream Mach number on the spike surface changes from approximately 1.5 at the $20 \%$ hole location to approximately 2.0 near the $80 \%$ injection location. However, due to altitude compensation the mach number between the $80 \%$ and $90 \%$ hole locations varies only slightly. Hence, another explanation must be sought to explain the differences in efficiency between these two locations.

An alternative insight into the cause of the high dependence on longitudinal hole location can be gleamed from secondary flow experiments performed on flat plates. For a flat plate, gaseous secondary injection creates a detached shock wave in front of the injection orifice and a low pressure region behind caused by over expansion of the primary injectant ${ }^{65} .{ }^{62}$ Thus, the region directly downstream of the injection hole counteracts the force imparted by the secondary injection. For a bell nozzle, the concavity of the surface where the secondary fluid is injected tends to extend the influence of the leading shock wave. Figure 12 clearly shows the high and low pressure regions around the injection orifice. The effects of the leading shock wave and the low pressure region due to over expansion tend to cancel out in a bell nozzle. ${ }^{64}$ Due to the convex surface of an aerospike, however, the effect of the leading bow shock tends to diminish away from the leading edge of the hole. Thus, downstream of the injection site, the net contribution to side force counteracts the secondary injection. The net side force can therefore be increased by decreasing the allowable area for the low pressure region behind the injection site. 


\section{II.E. Comparison of test results with thrust vectoring effectiveness in conical nozzles}

Thrust vectoring efficiency for gas injection into conical nozzles has been well established although data for gaseous injection is not as available as that for liquid injection. Work performed by Gunter and Farenholz on cold flow tests with a conical nozzle reached amplification factors of approximately $2.0{ }^{60}$ Walker, Stone and Shandler also performed cold flow tests, including some with carbon dioxide as a working fluid, and had side force amplification factors that ranged from approximately 1.8 to 3.0 , with the highest amplification factors gained by the smallest orifices. ${ }^{59}$ Inouye performed a series of hot gas injection tests and produced amplification factors generally between about 1.2 and 1.8 for a motor and secondary injection motor using red fuming nitric acid and unsymmetrical dimethylhydrazine. ${ }^{66}$

Although the amplification factors generated for the cold flow aerospike in this test are somewhat lower than for conical nozzles, it should be noted at all of these test series involved a much higher primary flow pressure ratio than those examined in the cold flow aerospike tests for this test series. Additionally, the high end amplification factors generated for conical nozzles generally corresponded to very small secondary orifice diameters. It is expected that variation of orifice size on an aerospike nozzle would likewise show a maximum at some orifice diameter.

In the author's opinion, the primary gain from thrust vectoring on an aerospike nozzle is the ability to use secondary injection jets as stand alone reaction control without use of the primary engine. When the primary thruster is fired then the additional benefits of flow amplification would be gained. A jet internal to a conventional nozzle would obviously not share this same operational advantage. This, coupled with the volumetric efficiency gains of aerospike nozzles makes aerospike nozzles with thrust vectoring a strong option for small satellite missions.

Table 2: Cold flow test specific impulse results.

\begin{tabular}{|c|c|c|c|}
\hline Test Series & $I_{s p}(\mathrm{~s})$ & $I_{s p}$ Uncertainty $(\mathrm{s}, 95 \%)$ & Amplification Factor \\
\hline Injection Location at $90 \%$ & 54.8 & \pm 1.9 & 1.39 \\
\hline Injection Location at $80 \%$ & 47.0 & \pm 1.9 & 1.19 \\
\hline Injection Location at $20 \%$ & 21.2 & \pm 1.7 & 0.54 \\
\hline Secondary Flow Only & 39.5 & \pm 1.8 & \\
\hline
\end{tabular}

\section{Computational Analysis}

Discuss reason for computational analysis...

Computational analysis was performed with the Viscous Upwind Algorithm for Complex Flow Analysis ${ }^{67}$ (VULCAN) code developed primarily by NASA Langley Research Center. 


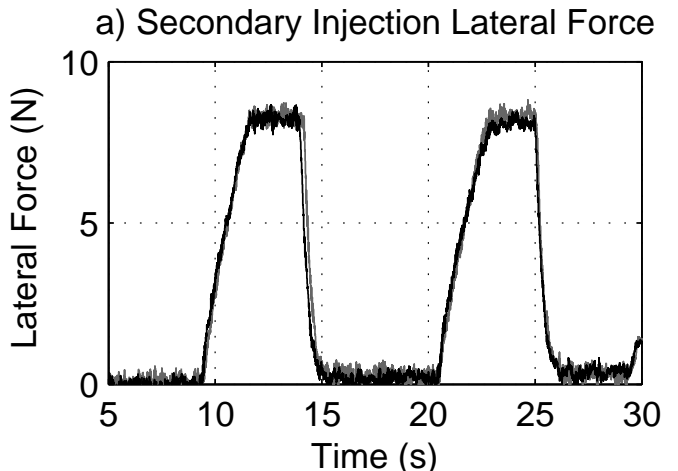

c) Secondary Injection Flow Temperature

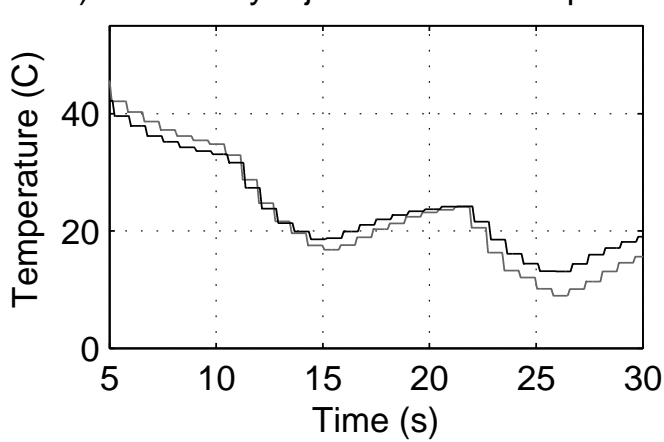

b) Secondary Injection Pressure

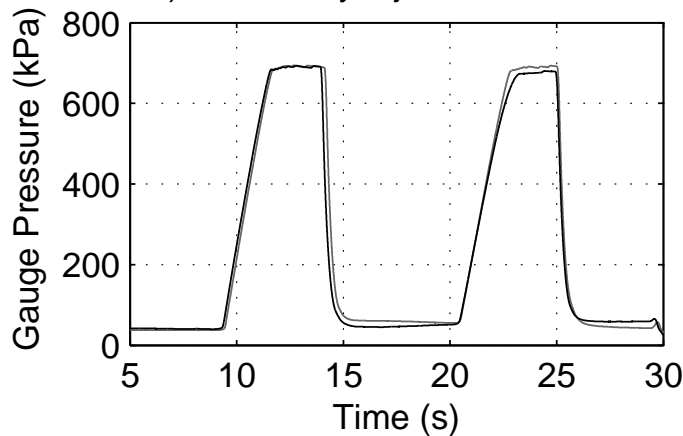

d) Secondary Injection Mass Flow

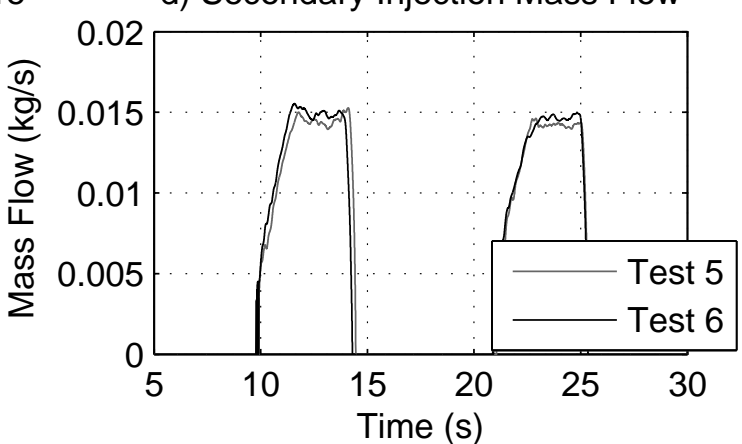

Figure 5: Side force and secondary injection pressure for $90 \%$ injection point.

a) Secondary Injection Lateral Force
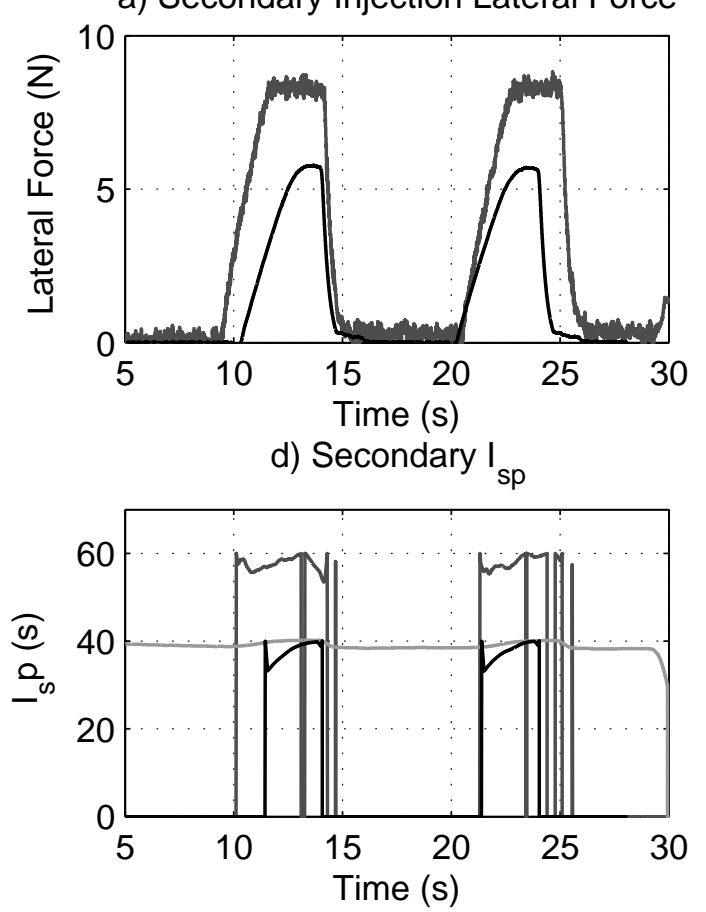

b) Secondary Injection Pressure

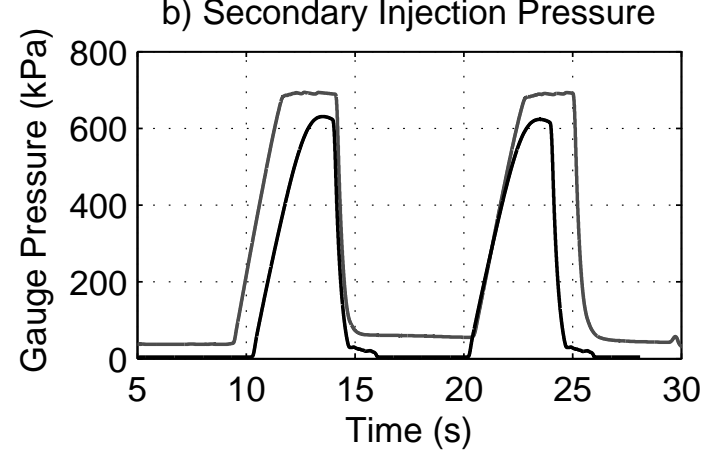

Test 5 Secondary Flow Test 5 Primary Flow Secondary Flow Only

Figure 6: Side force and secondary injection for $90 \%$ injection point for both primary flow on and secondary flow only configurations. 


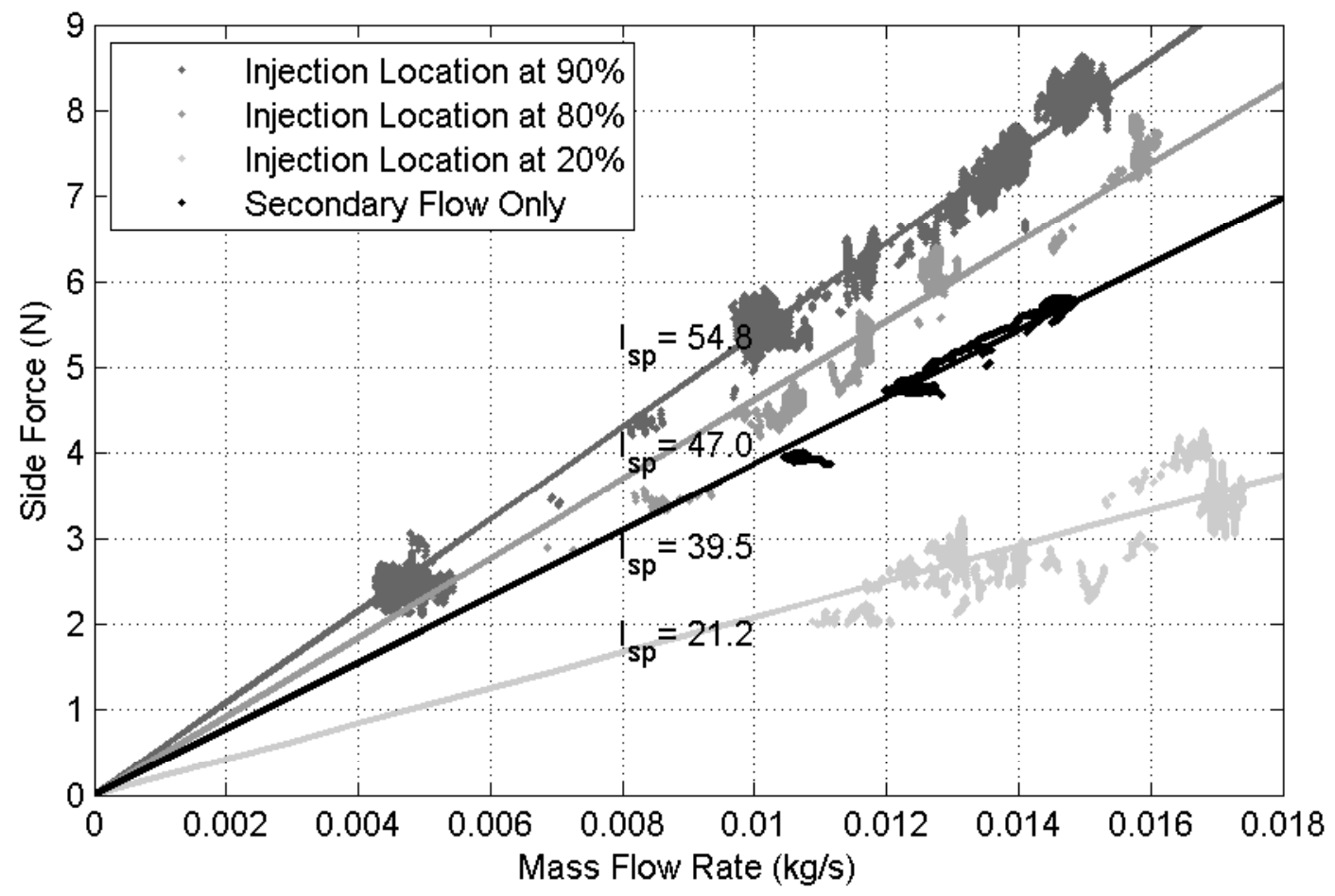

Figure 7: Cold flow secondary injection results and regressed specific impulses for various hole locations.

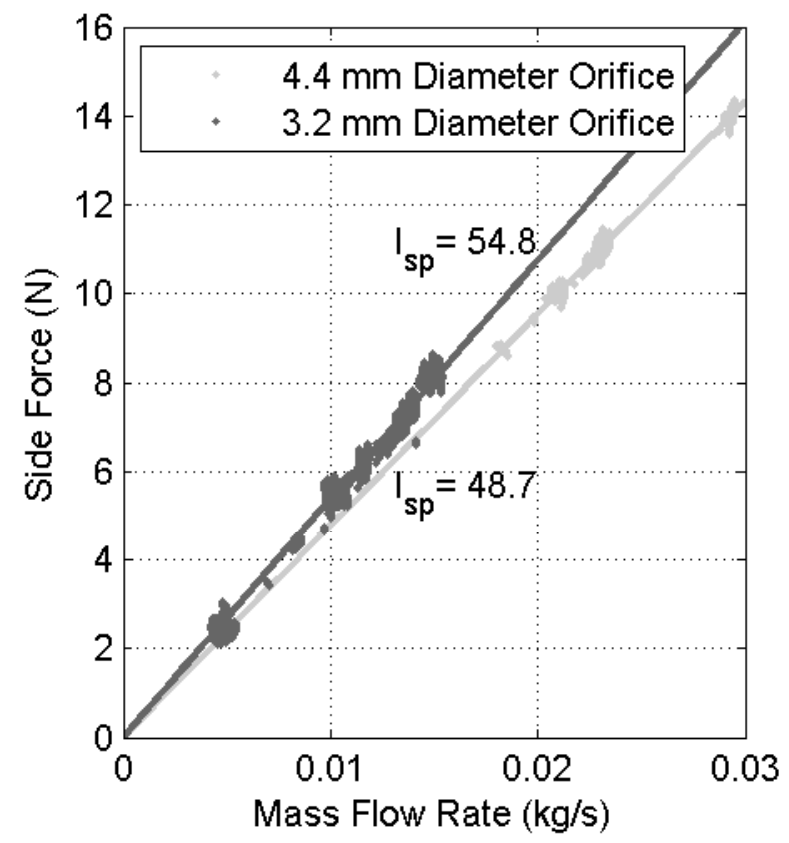

Figure 8: Cold flow secondary injection increased secondary orifice diameter results. 


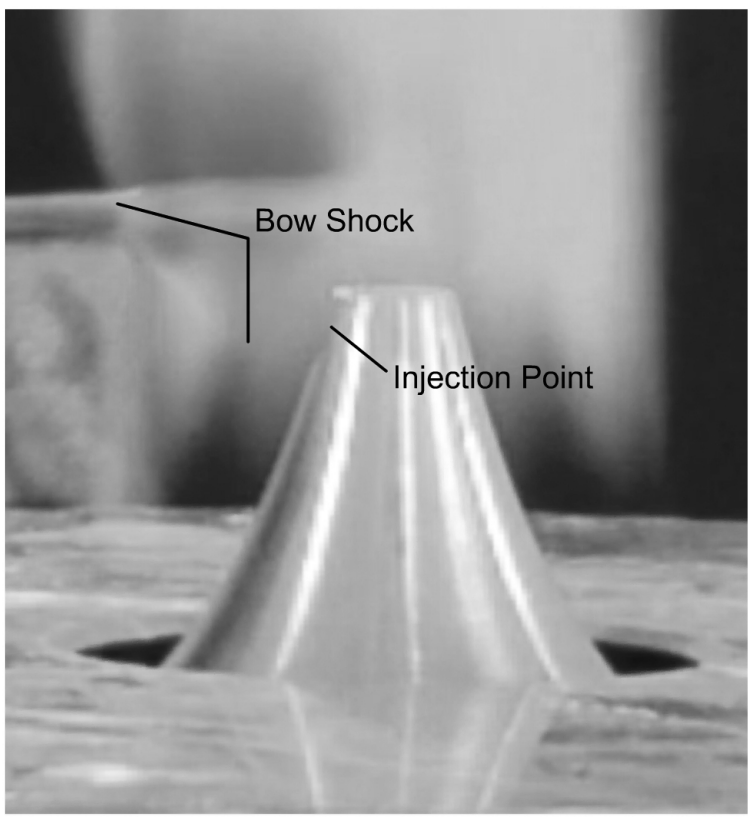

(a)

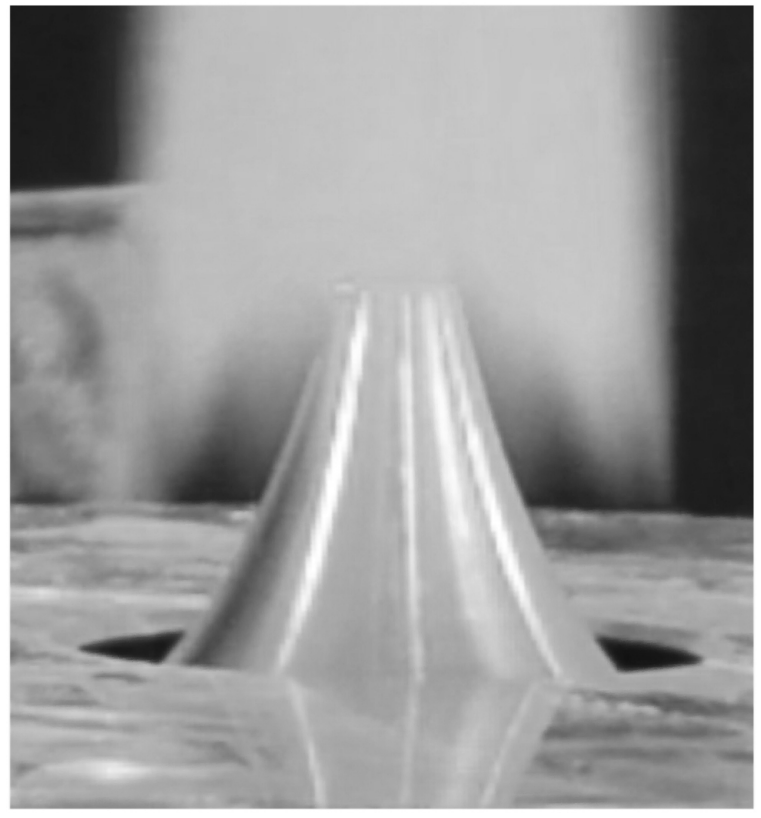

(b)

Figure 9: Aerospike cold flow test with $4.4 \mathrm{~mm}$ diameter orifice located at $90 \%$ of the length of the truncated aerospike. a) Thrust vectoring on, showing clear bow shock. b) Thrust vectoring off.

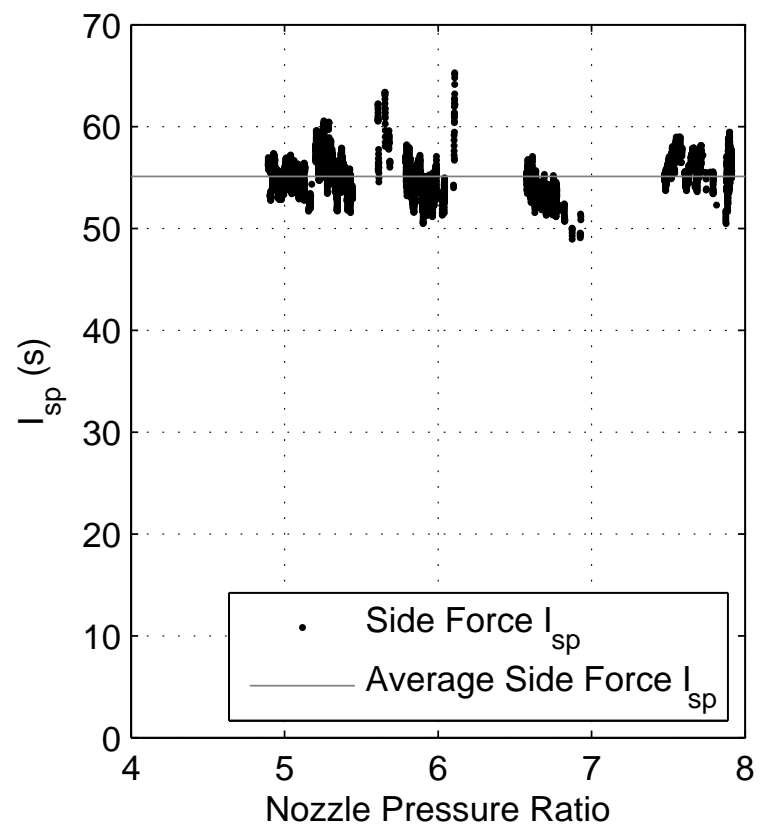

Figure 10: Cold flow specific impulse vs. nozzle pressure ratio. 


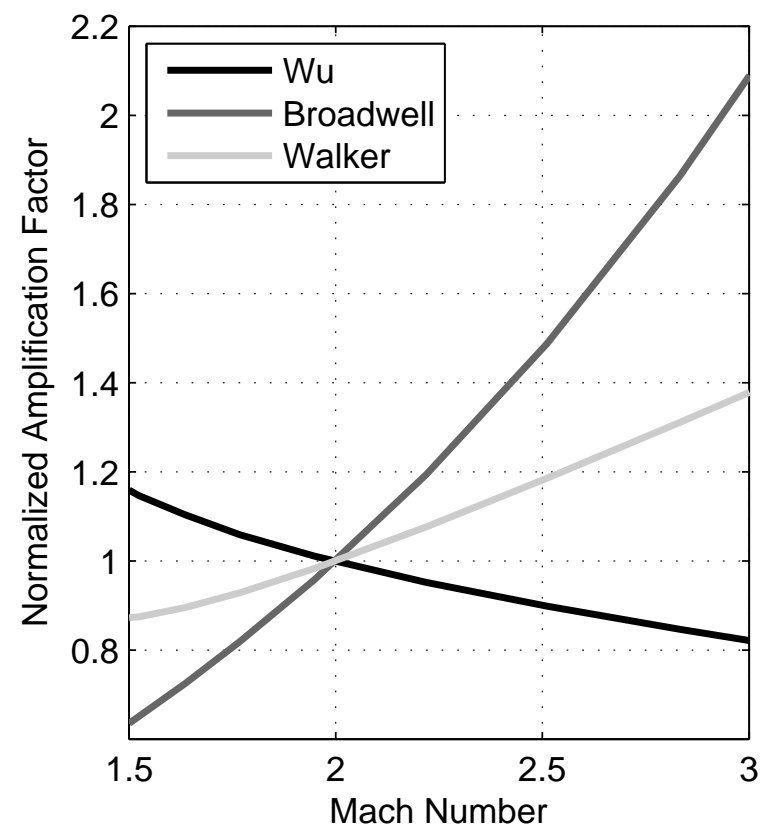

Figure 11: Normalized trends for dependence of side force amplification on primary flow Mach number for several theoretical models and a specific heat ratio of 2.0 .

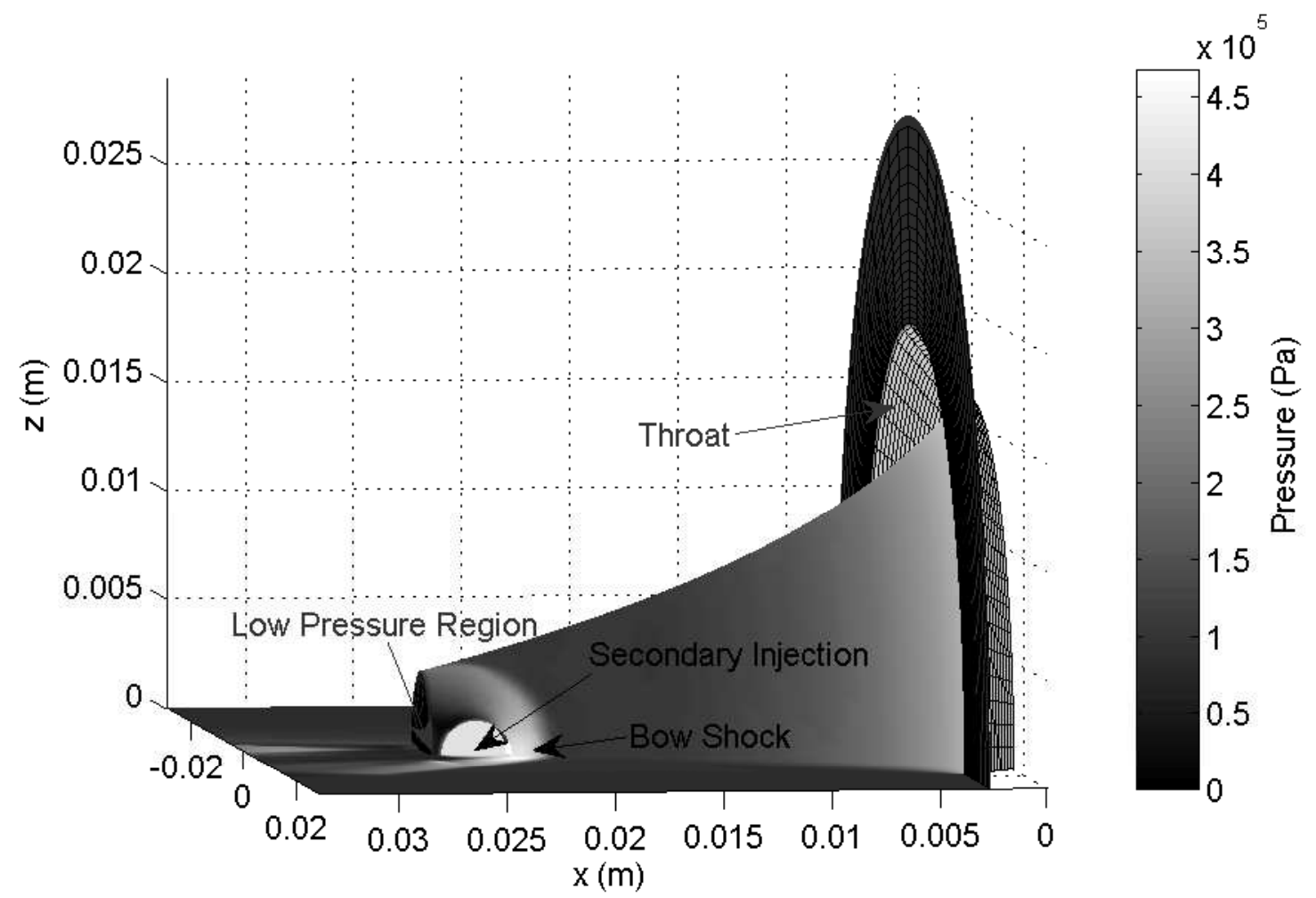

Figure 12: Bow shock and resulting static pressure from computational results on a truncated nozzle with $90 \%$ secondary injection location. 


\section{III.A. Computational Setup and Uncertainty}

Discuss grid and boundary conditions

Add grid pics.

Add table of parameters.

Discuss solution methods and accuracy.

Discuss iterative convergence criteria

\section{III.B. Computational Results}

Show pressure contours. Show pressure vs MOC. Show grid convergence. Plot axial and side forces for varying gammas. Show a graph of side force vs hole location for $80 \%$, (maybe 85 ) $90 \%$ and large $90 \%$ hole spike.

\section{Conclusion}

In order to enhance the thrust vectoring effectiveness of side-force injection on a three-dimensional aerospike nozzle, the injection site must be moved aft so that the convex flow expansion occurs downstream of the physical spike surface. This assertion is in direct contrast to what was previously known about side-injection on conventional nozzles. Data were collected for configurations with side injection port locations at $80 \%$ and $90 \%$ of the nozzle length; and significant force amplification factors were observed. The side-force specific impulse at the $90 \%$ port location is enhanced by nearly $40 \%$. The enhanced side force $I_{s p}$ means that the same control impulse can be achieved for significantly less propellant.

\section{References}

1"Final Report - Studies of Improved Saturn V Vehicles and Intermediate Payload Vehicles," Tech. rep., The Boeing Company - Space Division, 1996.

${ }^{2}$ Bendersky, C., "Space Shuttle Propulsion Issue, Staged Combustion Bell Versus Tap-Off or Gas-Generator Aerospike," .

${ }^{3}$ Berman, K. and Jr., F. W. C., "Perfomrance of Plug-Type Rocket Nozzles," ARS Journal, 1961, pp. 18-23.

${ }^{4}$ Hendershot, K. C., Sergeant, R. J., and Wilson, H. B., "A New Approach for Evaluating the Performance and Base Environment Characteristics of Nonconventional Rocket Propulsion Systems," AIAA, Vol. AIAA-67-256, 1967, pp. all.

5"Final Report, Advanced Aerodynamic Spike Configurations, Volume 1," Tech. rep., Rocketdyne Advanced Projects, 1967.

6"Final Report, Advanced Aerodynamic Spike Congifurations, Volume 2," Tech. rep., Rocketdyne Advanced Projects, 1967.

${ }^{7}$ Korte, J. J., Salas, A. O., Dunn, H. J., Alexandrov, N. M., Follett, W. W., Orient, G. E., and Hadid, A. H., "Multidisciplinary Approach to Aerospike Nozzle Design," Tech. rep., National Aeronautics and Space Administration, Langley Research Center, 1997. 
${ }^{8}$ Booth, T., Vilja, J. O., Cap, D. P., and McGill, R. J., "The Design of Linear Aerospike Thrust Cells," AIAA, Vol. AIAA1993-2562, 1993, pp. all.

${ }^{9}$ Erickson, C., "Thrust Vector Control Selection in Aerospike Engines," AIA A Journal, Vol. 97-3307, 1997, pp. 1-6.

${ }^{10}$ Heald, D. A. and Hart, D. A., "Advanced Reusable Engine for SSTO," 27th AIAA/SAE/ASME Joint Propulsion Conference, 1991.

${ }^{11}$ Korte, J. J., "Parametric Model of an Aerospike Rocket Engine," Tech. rep., NASA-AIAA, 2000.

${ }^{12}$ Higdon, K. and Landrum, D. B., "Analysis of Annular Plug Nozzle Perfomrance and TVC," AIA A paper, Vol. AIAA2003-4908, 2003, pp. All.

${ }^{13}$ Ruf, J. and McDaniels, D., "Experimental Results for an Annular Aerospike with Differential Throttling," 5th International Symposium on Liquid Space Propulsion, 2003.

${ }^{14}$ Bui, T., Murray, J., Rogers, C., Bartel, S., Cesaroni, A., and Dennett, M., "Flight Research of an Aerospike Nozzle Using High Power Solid Rockets," 41st AIAA/ASME/SAE/ASEE Joint Propulsion Conference E Exhibit, 2005.

${ }^{15}$ Shark, S. C., Dennis, J. D., and Villarreal, J. K., "Experimental Performance Analysis of a Toroidal Aerospike Nozzle Integrated with a N2O/HTPB Hybrid Rocket Motor," 46th AIAA/ASME/SAE/ASEE Joint Propulsion Conference E Exhibit, 2010.

${ }^{16}$ Stoffel, J. R., "Experimental and Theoretical Investigation of Aerospike Nozzles in a Hybrid Rocket Propulsion System," 47th AIAA Aerospace Sciences Meeting, 2009.

${ }^{17}$ Lemieux, P., "Development of a Reusable Aerospike Nozzle for Hybrid Rocket Motors," 39th AIAA Fluid Dynamics Conference, 2009.

${ }^{18}$ Lemieux, P., "Nitrous Oxide Cooling in Hybrid Rocket Nozzles," Progress in Aerospace Sciences, Vol. 46, 2009, pp. 106115.

${ }^{19}$ Ladeinde, T. and Chen, H., "Performance Comparison of a Full-Length and a Truncated Aerospike Nozzle," 46th AIAA/ASME/SAE/ASEE Joint Propulsion Conference \& Exhibit, 2010.

${ }^{20}$ Besnard, E., Chen, H. H., and Mueller, T., "Design, Manufacturing and Test of a Plug Nozzle Rocket Engine," AIAA paper, Vol. AIAA-2002-4038, 2002, pp. ALL.

${ }^{21}$ Besnard, E. and Garvey, J., "Aerospike Engines for Nanosat and Small Launch Vehicles (NLV/SLV),"Space 2004 Conference \& Exhibit, 2004.

${ }^{22}$ Besnard, E. and Garvey, J., "Development and Flight-Testing of Liquid Propellant Aerospike Engines," 40th AIAA/ASME/SAE/ASEE Joint Propulsion Conference and Exhibit, 2004.

${ }^{23}$ Wilson, A., Clark, J., Besnard, E., and Baker, M., "CFD Analysis of a Multi-Chamber Aerospike Engine in OverExpanded, Slipstream Conditions," 45th AIAA/ASME/SAE/ASEE Joint Propulsion Conference \& Exhibit, 2009.

${ }^{24}$ Schoyer, H. F. R., "Thrust Vector Control for (Clustered Modules) Plug Nozzles: Some Considerations," Journal of Propulsion and Power, Vol. 16, 2000, pp. 196-201.

${ }^{25}$ Hallard, R. and Merienne, M. C., "Aerospike Nozzle Tests," Proceedings of the Third European Symposium on Aerodynamics for Space Vehicles, Vol. 426, 1998, pp. 387-394.

${ }^{26}$ Fick, M., "Performance Modeling and Systems Aspects of Plug Cluster Nozzles," 34th AIAA/ASME/SAE/ASEE Joint Propulsion Conference \& Exhibit, 1998.

${ }^{27}$ Fick, M. and Schmucker, R. H., "Remarks on Plug Cluster Nozzles," 31st AIAA/ASME/SAE/ASEE Joint Propulsion Conference and Exhibit, Vol. AIAA 95-2694, 1995.

${ }^{28}$ Hagemann, G., Schley, C.-A., Odintsov, E., and Sobatchkine, A., "Nozzle Flowfield Analyses With Particular Regard to 3D-Plug Cluster Configurations," AIAA, Vol. AIAA-1996-2954, 1996, pp. all.

18 of 20 
${ }^{29}$ Hagemann, G., Immich, H., Nguyen, V., and Dumnov, G., "Advanced Rocket Nozzles," Journal of Propulsion and Power, Vol. 14, No. 5, September - October 1998, pp. 620-634.

${ }^{30}$ Rommel, T., Hagemann, G., Schley, C., Manski, D., and Krulle, G., "Plug Nozzle Flowfield Calculations for SSTO Applications," 31st Joint Propulsion Conference and Exhibit, AIAA 95-2784, 1995.

${ }^{31}$ Sorge, R., Carmicino, C., and Nocito, A., "Design of a Lab-Scale Cooled Two-Dimensional Plug Nozzle for Eperimental Tests," 38th AIAA/ASME/SAE/ASEE Joint Propulsion Conference \& Exhibit, 2002.

${ }^{32}$ Nasuti, F., Geron, M., and Paciorri, R., "Three Dimensional Features of Clustered Plug Nozzle Flows," 39th AIAA/ASME/SAE/ASEE Joint Propulsion Conference \& Exhibit, 2003.

${ }^{33}$ Nasuti, F. and Onofri, M., "Analysis of In-Flight Behavior of Truncated Plug Nozzles," 36th AIAA/ASME/SAE/ASEE Joint Propulsion Conference \& Exhibit, 2000.

${ }^{34}$ Onofri, M. and Nasuti, F., "Prediction of Open and Closed Wake in Plug Nozzles," Proc. 4th Europ Symp. Aeroghermodynamics for Space Applications, 2002.

${ }^{35}$ Onofri, M., "Plug Nozzles: Summary of Flow Features and Engine Performance," AIAA, Vol. 1-007, 2002, pp. 1-26.

${ }^{36}$ Fujii, K., Imai, K., and Sato, T., "Computational Analysis of the Flow Field Near the Boat-Tail Region of Annular Plug Nozzles," JSME International Journal, Vol. 45, 2002, pp. 745-751.

${ }^{37}$ Ito, T. and Fujii, K., "Flow Field and Performance Analysis of an Annular-Type Aerospike Nozzle with Base Bleeding," Transactions of the Japan Society for Aeronautical and Space Sciences, Vol. 46-151, 2003, pp. 17-23.

${ }^{38}$ Ito, T. and Fujii, K., "Numerical Analysis of the Base Bleed Effect on the Aerospike Nozzles," Transactions of the Japan Society for Aeronautical and Space Sciences, Vol. 46-151, 2003, pp. 17-23.

${ }^{39}$ Ito, T. and Fujii, K., "Flow Field Analysis of the Base Region of Axisymmetric Aerospike Nozzles," 39th AIAA Aerospace Sciences Meeting \& Exhibit, No. AIAA 2001-1051, 2001.

${ }^{40}$ Ito, T., Fujii, K., and Hagemann, G., "Numerical Investigation of the Side-Fence Effect on Linear Plug Nozzle Perfomrance," AIAA, Vol. AIAA 2004-4018, 2004, pp. all.

${ }^{41}$ Ito, T., Fujii, K., and Hayashi, A., "Computations of the Axisymmetric Plug Nozzle Flow Fields: Flow Structures and Thrust Performance," 17th AIAA Applied Aerodynamics Conference, No. AIAA 1999-3211, 1999.

${ }^{42}$ Miyamoto, H., Matsuo, A., and Kojima, T., "Effects fo Sidewall Configurations on Rectangular Plug Nozzle Performance," AIAA, Vol. AIAA-2006-4373, 2006, pp. all.

${ }^{43}$ Negishi, H. and Fujii, K., "Computational Analysis of the Effective Secondary-Flow Injections for the Plug-Nozzle Drag Reduction," 33rd AIAA Fluid Dynamics Conference and Exhibit, 2003.

${ }^{44}$ Tsutsumi, S., Yamaguchi, K., Teramoto, S., and Nagashima, T., "Clustering Effects on Performance and Heating of Linear Aerospike Nozzle," 45th AIA A Aerospace Sciences Meeting \& Exhibit ; 8-11 January 2007, Reno, Nevada, 2007.

${ }^{45}$ Taniguchi, M., Mori, H., Nishihira, R., and Niimi, T., "Experimental Analyses of flow Field Structures around Clustered Linear Aerospike Nozzles," American Institute of Physics Conference Proceedings, Vol. 762, 2005, pp. 349-354.

${ }^{46}$ Tomita, T., Takahashi, M., Onodera, T., and Tamura, H., "A Simple Performance Prediction Model of Clustered Linear Aerospike Nozzles," 37th AIAA/ASME/SAE/ASEE Joint Propulsion Conference E Exhibit, 2001.

${ }^{47}$ Tomita, T., Kumada, N., and Ogiwara, A., "A Conceptual System Design for a Linear Aerospike Engine Applied to a Future SSTO Vehicle," 46th AIAA/ASME/SAE/ASEE Joint Propulsion Conference E Exhibit, 2010.

${ }^{48}$ Tomita, T., Takahashi, M., Onodera, T., and Tamura, H., "Effects of Base Bleed on Thrust Perfomrance of a Linear Aerospike Nozzle," 35th AIAA/ASME/SAE/ASEE Joint Propulsion Conference and Exhibit, No. AIAA 1999-2586, 1999.

${ }^{49}$ Chang-Hui, W., Liu, Y., and Qin, L.-Z., "Aerospike nozzle contour design and its performance validation," Acta Astronautica, Vol. 64, 2009, pp. 1264-1275.

19 of 20

American Institute of Aeronautics and Astronautics 
${ }^{50}$ Chun-Guang, J., Yu, L., Chang-Hui, W., Wen-Bo, X., and Zhen, L., "A Study for Thrust Vector Control of Aerospike Nozzle Based on Second Injection," Journal of Propulsion Technology, Vol. 30-1, 2009, pp. 66-71.

${ }^{51}$ Spring, J., Xiao, P., Yu, L., and Yunfei, L., "Plug Nozzle Thrust Vector Control Study," Technological Sciences, Vol. 3, 2009, pp. 505-510.

${ }^{52} \mathrm{Li}$, J., Liu, Y., Liao, Y., Wang, C., Wang, Y., and Wang, N., "Experimental and Numerical Study on Two Dimensional Plug Nozzle," 46th AIAA/ASME/SAE/ASEE Joint Propulsion Conference 86 Exhibit, 2010.

${ }^{53}$ Yu, L., Wuye, D., Zhengke, Z., Lizi, Q., and Yibai, W., "Numerical Investigation on Linear Aerospike Nozzles," 37th AIAA/ASME/SAE/ASEE Joint Propulsion Conference and Exhibit, 2001.

${ }^{54}$ Karthikeyan, N., Verma, S. B., and Venkatakrishnan, L. V., "Experimental Investigation of the Acoustics of an Annular Aerospike Nozzle Flow," 15th AIAA/CEAS Aeroacoustics Conference (30th AIAA Aeroacoustics Conference), 2009.

${ }^{55}$ Verma, S. B., "Performance Characteristics of an Annular Conical Aerospike Nozzle with Freestream Effect," 44 th AIAA/ASME/SAE/ASEE Joint Propulsion Conference \& Exhibit, 2008.

${ }^{56}$ Kraiko, A. N. and Tillyayeva, N. I., "Contouring Spike Nozzles and Determining the Optimal Direction of their Primary Flows," Fluid Dynamics, Vol. 42-2, 2007, pp. 321-329.

${ }^{57}$ Naghib-Lahouti, A. and Tolouei, E., "Investigation of the Effect of Base Bleed on Thrust Performance of a Truncated Aerospike Nozzle In Off-Design Conditions," Eurpean Conference on Computational Fluid Dynamics, 2006.

${ }^{58}$ Ruf, J. H. and McConnaughey, P. K., "The Plume Physics Behind Aerospike Nozzle Altitude Compensation and Slipstream Effect," 33rd AIAA/ASME/SAE/ASEE Joint Propulsion Conference ES Exhibit, 1997.

${ }^{59}$ Walker, P. E., Stone, A. R., and Shander, M., "Secondary Gas Injection in a Conical Rocket Nozzle: Effect of Orifice Diameter and Molecular Weight of Injectant," Originally created at Johns Hopkins University; Reproduced by the Armed Services Technical Information Agency (now called Defense Technical Information Center).

${ }^{60}$ Gunter, F. L. and Farenholz, F. E., "Final Report on a Study of Rocket Thrust Control by Gas Injection," Tech. rep., Massachusetts Institute of Technology Naval Supersonic Laboratory, 1961.

${ }^{61}$ Broadwell, J. E., "Analysis of the Fluid Mechanics of Secondary Injection for Thrust Vector Control," AIAA Journal, Vol. 1, 1963, pp. 1067-1075.

${ }^{62}$ Guhse, R. D., "On Secondary Gas Injection in Supersonic Nozzles," Journal of Sp, Vol. 3, 1966, pp. 143-149.

${ }^{63}$ Vinson, P. W., Amick, J. L., and Liepman, H. P., "Interaction Effects Produced by Jet Exhaustion Laterally Near Base of Ogive-Cylinder Model in Supersonic Main Stream," Tech. rep., NASA and University of Michigan, 1959.

${ }^{64}$ Wu, J.-M., Chapkins, R. L., and Mager, A., "Approximate Analyses of Thrust Vector Control by Fluid Injection," ARS Journal, 1961, pp. $1677-1684$.

${ }^{65}$ Zukoski, E. E. and Spaid, F. W., "Secondary Injection of Gases into a Supersonic Flow," AIAA Journal, Vol. 2, 1964, pp. $1689-1697$.

${ }^{66}$ Inoyue, T., "Experiments on Rocket Thrust Vector Control by Hotgas Injection," Journal of Space, Vol. 3-4, 1966, pp. $737-739$.

67،VULCAN Home Page,” http://vulcan-cfd.larc.nasa.gov/ [retrieved 30 November 2010]. 